\title{
International databases and instructions for use
}

\author{
Marta Brunelli \\ Editorial Manager of History of Education \& Children's Literature (HECL) \\ Department of Education, Cultural Heritage and Tourism, \\ Università di Macerata
}

This document has been designed as an agile memorandum aimed to support the journals in field of humanities - whether the journals of longer tradition, or those that were born in the latest years which intend to undergo the evaluation process for inclusion in the most important international databases such as Web of Science and Scopus.

The memorandum has been prepared by ideally retracing all the steps and phases that the journal "History of Education \& Children's Literature" (HECL) has gone through since it was born in 2006 some of which it is still going through. All the information, then, have been checked on the databases' websites, and updated with the latest developments.

\section{MINIMUM CRITERIA NECESSARY FOR BEING INCLUDED IN THE INTERNATIONAL DATABASES}

1. Explicitly clarify the procedures, and the main responsibility, of the peer-review procedures of the journal;

2. Publish the names of the Referees' Committee acting as referees for each time considered (for each year; or for each two-year period; or three-year period etc.);

3. Provide the journal with an ISSN (or an e-ISSN, for the online journals) and make it visible on the journal's website;
4. Publish the journal on a regular basis;

5. Provide, for any article published, all the bibliographic information in English language too (i.e.: article titles, abstracts, keywords);

6. A sufficient number of articles should be written in English language (from at least one third of the articles, to a half of the articles);

7. For any author, the complete data (author affiliations, addresses and emails) should be provided in Roman script (in the paper-journal) and, if possible, should be publicly available (e.g. accessible through the journal's website); 
8. Publish in the website the journal's own "Publication code of ethics and malpractice statement based on the guidelines of the COPE-Committee of Publication Ethics. ${ }^{1}$

\section{THE CRITICAL FIRST TWO YEARS}

Scopus suggests to submit a journal only if the journal has a publication history of at least two years. In fact: "A journal suggestion may be rejected for review if the publication history is too short to review"2

For this reason, it is recommended to suggest a journal for the evaluation process only if the journal has accumulated a sufficient number of issues to be submitted for evaluation over the past two years - i.e. corresponding to: n. 2 issues of a yearly journal; or n. 4 issues of a half-yearly journal; and so on.

In this case, it is preferable to prepare in advance the pdfs referring to all the issues published in the last two years (i.e.: n. 2 pdfs for a yearly journal; n. 4 pdfs for a half-yearly journal; etc.) so that you will be ready when you are requested to submit pdfs (or to upload the pdfs on the online platform, such as in the case of SCOPUS) for evaluation process.

\author{
The "0 Phase" (I.E. After \\ PUBLISHING THE FIRST ISSUE) ${ }^{3}$ \\ Ulrich's
}

If your journal is an open-access journal, all the titles in the Directory of Open Access Journals (DOAJ) are already included in Ulrich's.

If your serial publication is not already tracked by Ulrich's, you can bring that title to the attention of the Ulrich's editorial team by sending an email to ulrichs@proquest.com.

In your email you have to include the name of the journal and any other information you may know about that publication - such as the name of the publisher or the provider who makes it available. An editor will follow up with the publisher or provider, and will attempt to get the most recent information about the publication. ${ }^{4}$

\section{EBSCO}

The international publisher EBSCO ${ }^{5}$ manages several databases - and when you get in touch with them, they will signal to you what databases are the most suitable to your journal. They are very interested in expanding the coverage of Ebsco's databases to new journals across the world.

\footnotetext{
${ }^{1}$ http://publicationethics.org/resources/guidelines

${ }^{2}$ https://www.elsevier.com/__data/assets/pdf_file/0006/95118/SC_ FAQ-content-selection-process-22092014.pdf

${ }^{3}$ Please note: the following deadlines have been settled just following this suggestion coming from Scopus, i.e. taking for granted that other databases also can request to analyse at least two years of publication history, in order to assess the quality of a journal.

${ }^{4}$ http://www .ulrichsweb.com/ulrichsweb/faqs.asp

${ }^{5}$ http://www.ebscohost.com/
} 
FIRST PHASE (AFTER 2 YEARS OF LIFE)

\section{ERIH Plus}

The new European Reference Index for the Humanities and Social Sciences is now open for new submissions of journals. On their website, in fact, they state that "new scientific journals can be submitted continuously".

Criteria for inclusion: ERIH Plus also states that, in order to assess a journal and in particular to determine its international nature (see: authorship), they need to review "the issues published during the last two years". 6

Please note: for being included in this database it is very important that a journal does not have a local authorship but at least a national authorship, i.e. no more than two thirds of the authors published in the journal can be from the same institution. ${ }^{7}$

Admission procedures: the submission can be made from editors, researchers and librarians, but anyone else can suggest a new journal for evaluation by submitting a proposal through the online form (that is very easy to use). The only prerequisite is that that "the suggestor" must register into the website to create a user account.
Submission of new journals through the online form: the submission of a new journal must contain the following information: 1 . ISSN, title, URL and language; 2 . Suggested discipline(s) of the journal (for a list of disciplines click here). It is possible to indicate two disciplines if a journal covers more than one. ${ }^{8}$

\section{SCOPUS $^{9}$}

Before suggesting a new journal please check if the journal possesses all the requirements needed, as illustrated above (see the aforementioned minimum criteria), i.e.:

The title should publish peerreviewed content.

The title should be published on a regular basis.

The title should have an ISSN that has been confirmed by the ISSN International Centre.

The title should have English language abstracts and article titles.

The title should have references in Roman script.

The title should have a publication ethics and publication malpractice statement.

Submission of new journals: journals can be suggested for inclusion in Scopus through an online suggestion form. 10

\footnotetext{
${ }^{6}$ With regard to the criteria for inclusion see the web-page: https://dbh.nsd.uib.no/ publiseringskanaler/erihplus/about/criteria_for_inclusion

${ }^{7}$ see also the Approval procedures: https://dbh.nsd.uib.no/publiseringskanaler/erihplus/ about/approval_procedures

${ }^{8}$ To suggest the title you have to register and, subsequently, to login in this page: https: //dbh.nsd.uib.no/publiseringskanaler/erihplus/login.

9 About the Scopus selection process see:http://www.elsevier.com/__data/assets/pdf_ file/0017/234332/SC_FAQ-content-selection-process-22092014.pdf .

${ }^{10}$ http://suggestor.step.scopus.com/suggestTitle/step1.cfm
} 
Please note that: "After suggesting a journal, you will receive an immediate acknowledgement email that confirms that the journal suggested has been received and will be considered for review. [...] I twill take 6-12 months before the review process is completed".

In this regard, remember that SCOPUS does not offer any tool (for example an online forms, which is offered, on the contrary, by Thomson Reuters. On this, see below), which allows publishers or editors to verify the status of the evaluation process. Consequently, after suggesting a title, you simply have to wait for being contacted by Scopus.

\section{WEB OF SCIENCE (WOS) ${ }^{11}$}

In general we can divide this long process into two steps.

WOS-Step n. 1: the evaluation of a journal for coverage in Web of Science begins with the signalling of the current issue of a journal. From this moment on, the publisher will deliver to Thomson Reuters three consecutive issues, each one as soon as published. The publisher can choose whether to deliver a paper-copy ${ }^{12}$, or to deliver a digital copy ${ }^{13}$. The observation of these (at least) three consecutive issues is aimed to establish the timeliness of the journal.

Once timeliness has been established, Thomson Reuters has the option to proceed with the other aspects of the evaluation process. In other words, Thomson Reuters has the option to proceed with what we call the WOSStep n. 2 (see here below).

\section{SECOND PHASE (AFTER 3 YEARS OF LIFE)}

\section{ERIH Plus (European Reference Index for the Humanities and Social Sciences)}

In this phase you should have already submitted the journal. So please wait for being contacted by ERIH Plus.

\section{SCOPUS}

In this phase you should have already submitted the journal. Please wait for being contacted by Scopus.

\section{WEB OF SCIENCE (WOS)}

In this phase you should have already submitted the journal, and Thomson Reuters should have established the timeliness of the journal.

As already said, once timeliness has been established, Thomson Reuters has the option to proceed with the other aspects of the evaluation process (WOS-Step n. 2). They clearly underline that this process rarely begins immediately, due to the high volume of journal submissions and the editorial priorities set

\footnotetext{
11 About the Thomson Reuters selection process see: http://wokinfo.com/essays/journalselection-process/.

12 See the instructions in: http://wokinfo.com/publisher_relations/journals/

13 See the following submission form: http://ip-science.thomsonreuters.com/info/journalsubmissionfront/.
} 
by Thomson Reuters for Web of Science coverage.

I suggest - after submitting that at least the sixth published issue of your journal - to request which is the state of the evaluation process. ${ }^{14}$ They will immediately reply to your request, and suggest what steps are necessary to be taken further.

WOS-Step n. 2. At the end of this phase of the evaluation process, they will inform you if your journal: 1. can not be indexed because it needs further adjustments;

2. can be accepted for indexation in one of the databases of WOS (such as, for the humanities sector, the "Arts and Humanities Index");

3. can be accepted for indexation also in JCR (the Journal Citation Reports, which assigns the Impact Factor).
If your journal meets all the requirements needed, the phase n. 2 could be completed within a shorttime (i.e. within two or three years).

The acceptation in JCR too, on the contrary, could need it may involve the extension of the "observation" by ISI because of many reasons - first of all, a low level of external citations (i.e. a low number of citation of the authors/articles published in your journal, by authors/articles published in journals indexed in WOS).

For journals in humanities field, entering into the last and final phase (JCR) could imply to wait for diverse years. But the most important thing, anyway, is to enter in the phase WOSStep $n .2$ and to remain in WOS, i.e. to carefully work in order to maintain all the requirements needed.

\footnotetext{
14 This is possible by filling out the online form "Journal evaluation state form": http://ipscience.thomsonreuters.com/info/jrneval-status/.
} 